\title{
Performance Evaluation of a Low-Grade Low-Heat-Rejection Diesel Engine with Crude Pongamia oil
}

\author{
Ch. Kesava Reddy, ${ }^{1}$ M. V. S. Murali Krishna, ${ }^{2}$ P. V. K. Murthy, ${ }^{3}$ and T. Ratna Reddy ${ }^{1}$ \\ ${ }^{1}$ Mechanical Engineering, Rayalaseema University, Andhra Pradesh, Kurnool 518502, India \\ ${ }^{2}$ Mechanical Engineering Department, Chaitanya Bharathi Institute of Technology, Gandipet, Andhra Pradesh, \\ Hyderabad 500075, India \\ ${ }^{3}$ Vivekananda Institute of Science and Information Technology, Shadnagar, Andhra Pradesh, Mahabubnagar 509216, India \\ Correspondence should be addressed to P. V. K. Murthy, krishnamurthy_venkata@yahoo.co.in
}

Received 2 December 2011; Accepted 2 January 2012

Academic Editor: C. J. Koroneos

Copyright (๑) 2012 Ch. Kesava Reddy et al. This is an open access article distributed under the Creative Commons Attribution License, which permits unrestricted use, distribution, and reproduction in any medium, provided the original work is properly cited.

\begin{abstract}
Investigations are carried out to evaluate the performance of a low heat rejection (LHR) diesel engine with ceramic coated cylinder head [ceramic coating of thickness 500 microns is done on inside portion of cylinder head] with different operating conditions [normal temperature and pre-heated temperature] of crude pongamia oil (CPO) with varied injection pressure and injection timing. Performance parameters and pollution levels are determined at various magnitudes of brake mean effective pressure. Combustion characteristics at peak load operation of the engine are measured with special pressure-crank angle software package. Conventional engine (CE) showed deteriorated performance, while LHR engine showed improved performance with CPO operation at recommended injection timing and pressure and the performance of both version of the engine is improved with advanced injection timing and at higher injection pressure when compared with CE with pure diesel operation. The optimum injection timing is $31^{\circ}$ bTDC for conventional engine while it is $29^{\circ}$ bTDC with LHR engine with vegetable oil operation. Peak brake thermal efficiency increased by $5 \%$, smoke levels decreased by $2 \%$ and $\mathrm{NO}_{x}$ levels increased by $40 \%$ with CPO operation on LHR engine at its optimum injection timing, when compared with pure diesel operation on CE at manufacturer's recommended injection timing.
\end{abstract}

\section{Introduction}

The civilization of a particular country has come to be measured on the basis of the number of automotive vehicles being used by the public of the country. The tremendous rate at which population explosion is taking place imposes expansion of the cities to larger areas, and common man is forced these days to travel long distances even for their routine works. This in turn us causing an increase in vehicle population at an alarm rate thus bringing in pressure on government to spend huge foreign currency for importing crude petroleum to meet the fuel needs of the automotive vehicles. The large amount of pollutants emitting out from the exhaust of the automotive vehicles run on fossil fuels is also increasing as this is proportional to number of vehicles. In view of heavy consumption of diesel fuel involved in not only transport sector but also in agricultural sector and also fast depletion of fossil fuels, the search for alternate fuels has become pertinent apart from effective fuel utilization which has been the concern of the engine manufacturers, users, and researchers involved in combustion and alternate fuel research. The idea of using vegetable oil as fuel has been around from the birth of diesel engine. Rudolph diesel, the inventor of the engine that bears his name, experimented with fuels ranging from powdered coal to peanut oil. Experiments were conducted [1-8] with CE with vegetable oils and blends of vegetable oil and diesel and reported that performance was deteriorated with $\mathrm{CE}$.

It is well-known fact that about $30 \%$ of the energy supplied is lost through the coolant and 30\% is wasted through friction and other losses, thus leaving only $30 \%$ of energy utilization for useful purposes. In view of the above, the major thrust in engine research during the last one or two decades has been on development of LHR engines. Several methods 
adopted for achieving LHR to the coolant are (i) using ceramic coatings on piston, liner, and cylinder head (ii) creating air gap in the piston and other components with lowthermal-conductivity materials like superni, cast iron and mild steel, and so forth. Ceramic coatings provided adequate insulation and improved brake-specific fuel consumption (BSFC) which was reported by various researchers [9-12]. Dhinagar et al. [13] conducted investigations of LHR engines with varying degree of insulation such as ceramic coated engine, air gap-insulated piston engine, and air gap-insulated liner engine with pure diesel operation and reported improvement in the performance of the engine with LHR version of the engine. Bhaskar et al. [14] conducted experimental investigations on jatropha oil with LHR engine, which consisted of ceramic-coated cylinder head and air gap cylinder liner and reported that performance was improved and pollution levels of hydrocarbon and smoke decreased with LHR version of the engine with jatropha oil when compared with CE with pure diesel operation. Ignition improvers to jatropha oil further improved the performance and reduced the pollution levels. Jabez Dhinagar et al. [15] tested three vegetable oils, neem oil, rice bran oil, and karanja oil, in LHR engine and reported that performance of vegetable oils was improved with preheating. Hanbey Hazar [16] conducted investigations on LHR engine with the cylinder head, exhaust, and inlet valves of a diesel engine were coated with the ceramic material $\mathrm{MgO}-\mathrm{ZrO}_{2}$ by the plasma spray method, while the piston surface was coated with $\mathrm{ZrO}_{2}$. Thus, a thermal barrier was provided for the elements of the combustion chamber with these coatings. Using identical coated and uncoated engines, the effects of canola methyl ester produced by the transesterification method and ASTM no. 2D fuel on engine performance and exhaust emissions were studied. Tests were performed on the uncoated engine and then repeated on the coated engine, and the results were compared. An increase in engine power and decrease in specific fuel consumption, as well as significant improvements in exhaust gas emissions and smoke density, were observed for all test fuels used in the coated engine compared with that of the uncoated engine. Rajendra Prasath et al. [17] conducted experiments on LHR engine with partially stabilized zirconia coating on the inner potion of cylinder head with biodiesel and reported that performance was improved with LHR engine.

Little literature is available in evaluating the performance of LHR engine with ceramic-coated cylinder head with varying engine parameters at different operating conditions of the vegetable oil. The present paper attempts to evaluate the performance of LHR engine, which contains ceramic-coated cylinder head with different operating conditions of CPO with varying engine parameters of change of injection pressure and timing and compared with CE at recommended injection timing and injection pressure.

\section{Experimental Programme}

The properties of vegetable oil are shown in Table 1.

Experimental setup used for the investigations of LHR diesel engine with crude pongamia oil (CPO) is shown in
Figure 1. Partially stabilized zirconium (PSZ) of thickness 500 microns is coated by means of plasma coating technique on the inner portion of cylinder head. CE has an aluminum alloy piston with a bore of $80 \mathrm{~mm}$ and a stroke of $110 \mathrm{~mm}$. The rated output of the engine is $3.68 \mathrm{~kW}$ at a rate speed of $1500 \mathrm{rpm}$. The compression ratio is $16: 1$, and manufacturer's recommended injection timing and injection pressures are $27^{\circ} \mathrm{bTDC}$ and $190 \mathrm{bar}$, respectively. The fuel injector has 3 holes of size $0.25 \mathrm{~mm}$. The combustion chamber consists of a direct injection type with no special arrangement for swirling motion of air. The engine is connected to electric dynamometer for measuring brake power of the engine. Burette method is used for finding fuel consumption of the engine. Air consumption of the engine is measured by air-box method. The naturally aspirated engine is provided with water cooling system in which inlet temperature of water is maintained at $60^{\circ} \mathrm{C}$ by adjusting the water flow rate. Engine oil is provided with a pressure feed system. No temperature control is incorporated, for measuring the lube oil temperature. Copper shims of suitable size are provided in between the pump body and the engine frame, to vary the injection timing, and its effect on the performance of the engine is studied, along with the change of injection pressures from 190 bar to 270 bar (in steps of 40 bar) using nozzle testing device. The maximum injection pressure is restricted to 270 bar due to practical difficulties involved. Exhaust gas temperature (EGT) is measured with thermocouples made of iron and iron-Constantan. Pollution levels of smoke and $\mathrm{NO}_{x}$ are recorded by AVL smoke meter and, Netel chromatograph $\mathrm{NO}_{x}$ analyzer, respectively, at the peak load operation of the engine. Piezoelectric transducer, fitted on the cylinder head to measure pressure in the combustion chamber is connected to a console, which in turn is connected to Pentium personal computer. TDC encoder provided at the extended shaft of the dynamometer is connected to the console to measure the crank angle of the engine. A special $P-\theta$ software package evaluates the combustion characteristics such as peak pressure (PP), time of occurrence of peak pressure (TOPP), maximum rate of pressure rise (MRPR), and time of occurrence of maximum rate of pressure rise (TOMRPR) from the signals of pressure and crank angle at the peak load operation of the engine. Pressure-crank angle diagram is obtained on the screen of the personal computer.

\section{Results and Discussion}

3.1. Performance Parameters. The variation of brake thermal efficiency (BTE) with brake mean effective pressure (BMEP) in the conventional engine $(\mathrm{CE})$ with $\mathrm{CPO}$, at various injection timings at an injection pressure of $190 \mathrm{bar}$, is shown in Figure 2. The variation of BTE with BMEP with pure diesel operation on $\mathrm{CE}$ at recommended injection timing is also shown for comparison purpose. CE with vegetable oil showed the deterioration in the performance for entire load range when compared with the pure diesel operation on $\mathrm{CE}$ at recommended injection timing. Although carbon accumulations on the nozzle tip might play a partial role for the general trends observed, the difference of viscosity between the diesel and vegetable oil provided a possible explanation 
TABLe 1: Properties $f$ the nonedible vegetable oil and diesel.

\begin{tabular}{lcccc}
\hline Test fuel & Viscosity at $25^{\circ} \mathrm{C}$ (centipoise) & Density at $25^{\circ} \mathrm{C}$ & Cetane number & Calorific value $(\mathrm{kJ} / \mathrm{kg})$ \\
\hline Diesel & 12.5 & 0.84 & 55 & 42000 \\
Pongamia oil (crude) & 125 & 0.91 & 48 & 37100 \\
\hline
\end{tabular}

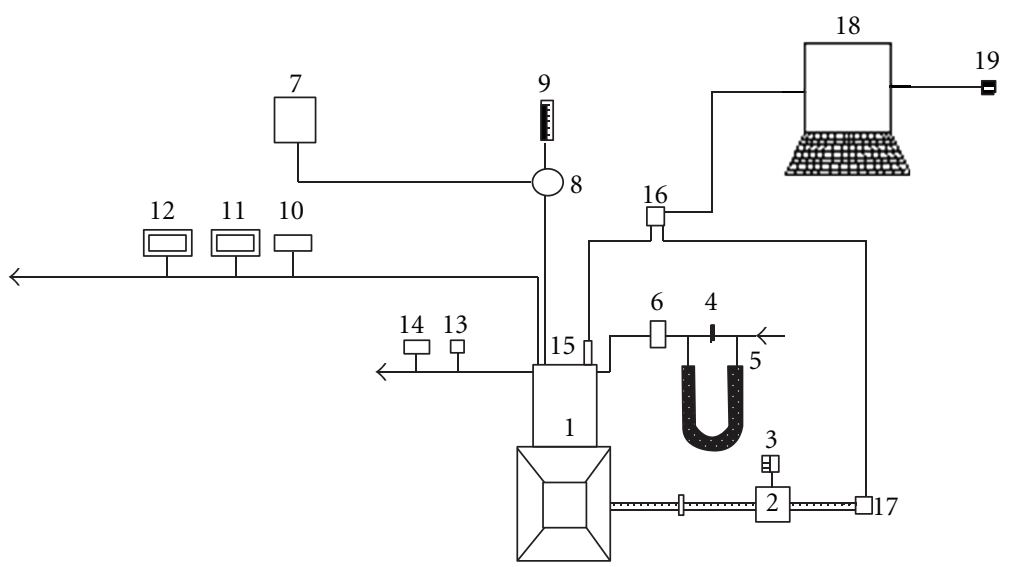

Figure 1: Experimental setup. (1) Engine, (2) electrical dynamo meter, (3) load box, (4) orifice meter, (5) U-tube water manometer, (6) air box, (7) fuel tank, (8) preheater, (9) burette, (10) exhaust gas temperature indicator, (11) AVL smoke meter, (12) Netel chromatograph $\mathrm{NO}_{x}$ analyzer, (13) outlet jacket water temperature indicator, (14) outlet-jacket water flow meter, (15) Piezoelectric pressure transducer, (16) console, (17) TDC encoder, (18) Pentium personal computer, and (19) printer.

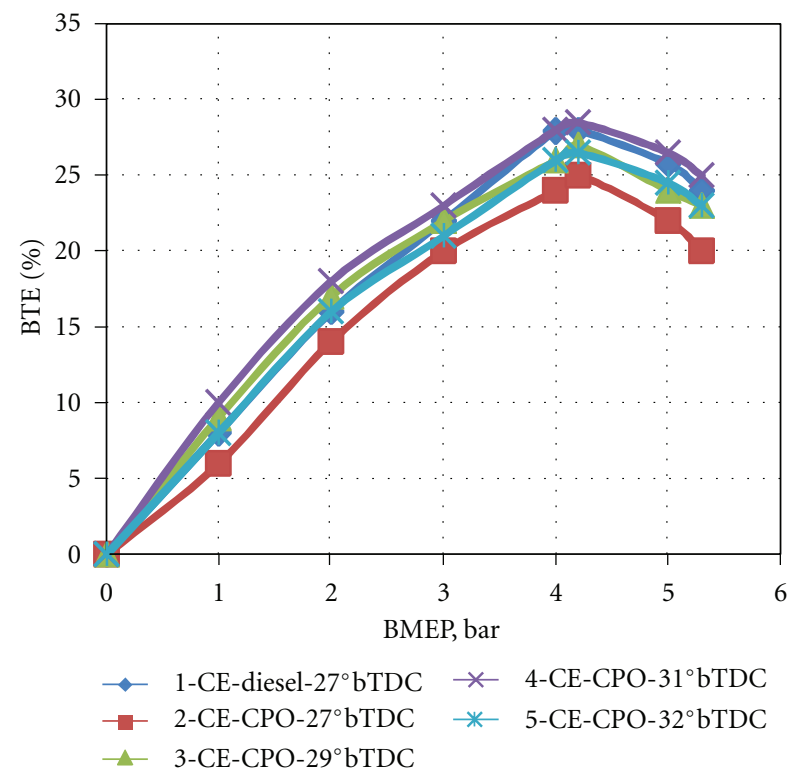

FIGURE 2: Variation of brake thermal efficiency (BTE) with brake mean effective pressure (BMEP) in conventional engine $(\mathrm{CE})$ at different injection timings with crude pongamia oil (CPO) operation.

for the deterioration in the performance of the engine with vegetable oil operation. In addition, less air entrainment by the fuel spay suggested that the fuel spray penetration might increase and resulted in more fuel reaching the combustion chamber walls. Furthermore, droplet mean diameters (expressed as the Sauter mean) are larger for vegetable oil leading to reduction in the rate of heat release as compared with diesel fuel. This also contributed to the higher ignition (chemical) delay of the vegetable oil due to lower cetane number. According to the qualitative image of the combustion under the crude vegetable oil operation with $\mathrm{CE}$, the lower BTE is attributed to the relatively retarded and lower heat release rates. BTE increased with the advancing of the injection timing in CE with the vegetable oil at all loads, when compared with $\mathrm{CE}$ at the recommended injection timing and pressure. This is due to initiation of combustion at earlier period and efficient combustion with increase of air entrainment in fuel spray giving higher BTE. BTE increased at all loads when the injection timing is advanced to $31^{\circ} \mathrm{bTDC}$ in the CE at the normal temperature of vegetable oil. The increase of BTE at optimum injection timing over the recommended injection timing with vegetable oil with $\mathrm{CE}$ could be attributed to its longer ignition delay and combustion duration. BTE increased at all loads when the injection timing is advanced to $31^{\circ} \mathrm{bTDC}$ in $\mathrm{CE}$, at the preheated temperature of CPO. That, too, the performance is improved further in CE with the preheated vegetable oil for entire load range when compared with normal vegetable oil. Preheating of the vegetable oil reduced the viscosity, which improved the spray characteristics of the oil and reduced the impingement of the fuel spray on combustion chamber walls, causing efficient combustion thus improving BTE.

The variation of BTE with BMEP in the LHR engine with $\mathrm{CPO}$, at various injection timings at an injection pressure of 190 bar, is shown in Figure 3. LHR version of the engine showed the marginal improvement in the performance for entire load range compared with $\mathrm{CE}$ with pure diesel operation. High cylinder temperatures helped in better evaporation and faster combustion of the fuel injected into 


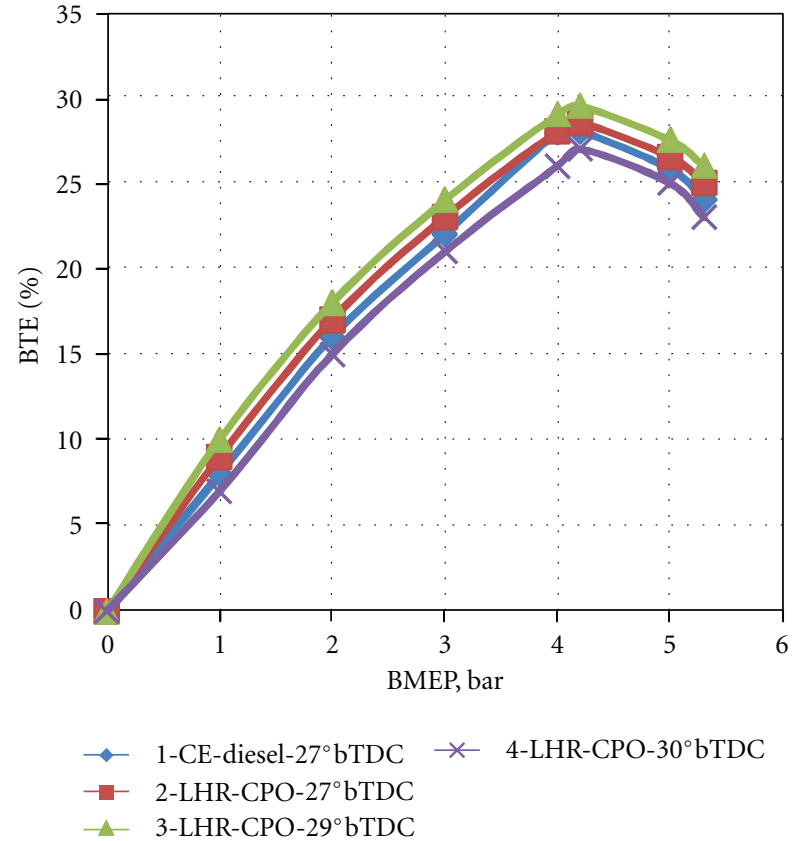

FIGURE 3: Variation of brake thermal efficiency (BTE) with brake mean effective pressure (BMEP) in low heat rejection (LHR) engine at different injection timings with crude pongamia oil (CPO) operation.

the combustion chamber. Reduction of ignition delay of the vegetable oil in the hot environment of the LHR engine improved heat release rates and efficient energy utilization. Preheating of vegetable oil improves performance further in LHR version of the engine. The optimum injection timing is found to be $29^{\circ}$ bTDC with LHR engine with normal CPO. Since the hot combustion chamber of LHR engine reduced ignition delay and combustion duration, and hence the optimum injection timing is obtained earlier with LHR engine when compared with $\mathrm{CE}$ with the vegetable oil operation.

Injection pressure is varied from 190 bars to 270 bars to improve the spray characteristics and atomization of the vegetable oils, and injection timing is advanced from 27 to $34^{\circ} \mathrm{bTDC}$ for CE and LHR engine. Table 2 shows the variation of BTE with injection pressure and injection timing at different operating conditions of $\mathrm{CPO}$ with different configurations of the engine. BTE increases with increase in injection pressure in both versions of the engine at different operating conditions of the vegetable oil.

The improvement in BTE at higher injection pressure is due to improved fuel spray characteristics. However, the optimum injection timing is not varied even at higher injection pressure with LHR engine, unlike the CE. Hence it is concluded that the optimum injection timing is $31^{\circ} \mathrm{bTDC}$ at $190 \mathrm{bar}, 30^{\circ} \mathrm{bTDC}$ at $230 \mathrm{bar}$, and $29^{\circ} \mathrm{bTDC}$ at 270 bar for CE. The optimum injection timing for LHR engine is $29^{\circ} \mathrm{bTDC}$ irrespective of injection pressure. Peak BTE is higher in LHR engine when compared with $\mathrm{CE}$ with different operating conditions of the vegetable oils.

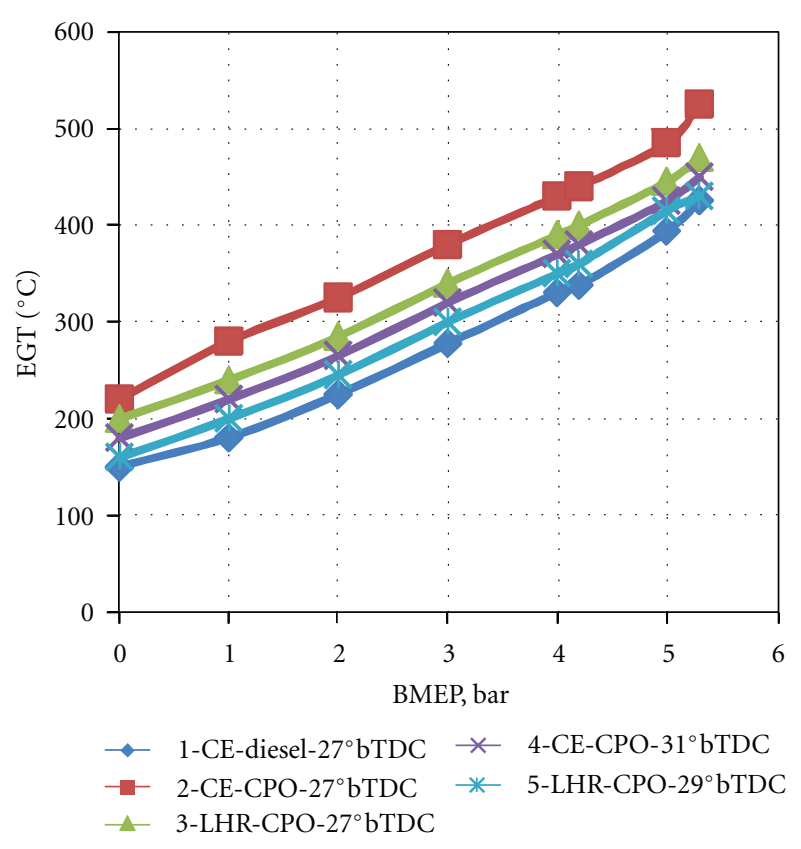

FIGURE 4: Variation of exhaust gas temperature (EGT) with brake mean effective pressure (BMEP) in conventional engine (CE) and low-heat-rejection (LHR) engine at recommend injection timing and optimized injection timings with crude pongamia oil (CPO) operation.

Figure 4 shows the variation of the exhaust gas temperature (EGT) with BMEP in CE and LHR engine with CPO at normal temperature at the recommended and optimized injection timings at an injection pressure of 190 bar. CE with $\mathrm{CPO}$ at the recommended injection timing recorded higher EGT at all loads compared with CE with pure diesel operation. Lower heat release rates and retarded heat release associated with high specific energy consumption caused increase in EGT in CE. Ignition delay in the CE with different operating conditions of vegetable oil increased the duration of the burning phase. LHR engine recorded lower value of EGT when compared with CE with vegetable oil operation. This is due to reduction of ignition delay in the hot environment with the provision of the insulation in the LHR engine, which caused the gases expansion in the cylinder giving higher work output and lower heat rejection. This showed that the performance is improved with LHR engine over CE with vegetable oil operation. The magnitude of EGT at peak load decreased with advancing of injection timing and with increase of injection pressure in both versions of the engine with vegetable oil. Preheating of the vegetable oil further reduced the magnitude of EGT, compared with normal vegetable oil in both versions of the engine. Table 3 shows the variation of EGT with injection pressure and injection timing at different operating conditions of $\mathrm{CPO}$ with different configurations of the engine. EGT decreases with increase in injection pressure and injection timing with both versions of the engine, which confirms that performance is increased with injection pressure. Preheating of vegetable oil decreases EGT in both versions of the engine. 
TABLE 2: The variation of peak BTE with injection timing and injection pressure in the conventional and LHR engines at different operating conditions of the vegetable oil.

\begin{tabular}{|c|c|c|c|c|c|c|c|c|c|c|c|c|c|}
\hline \multirow{5}{*}{ Injection timing ( ${ }^{\circ}$ bTDC) } & \multirow{5}{*}{ Test fuel } & \multicolumn{12}{|c|}{ Peak BTE (\%) } \\
\hline & & \multirow{2}{*}{\multicolumn{6}{|c|}{$\begin{array}{l}\text { Conventional engine } \\
\text { Injection pressure (bars) }\end{array}$}} & \multirow{2}{*}{\multicolumn{6}{|c|}{$\begin{array}{c}\text { LHR engine } \\
\text { Injection pressure (bars) }\end{array}$}} \\
\hline & & & & & & & & & & & & & \\
\hline & & \multicolumn{2}{|c|}{190} & \multicolumn{2}{|c|}{230} & \multicolumn{2}{|c|}{270} & \multicolumn{2}{|c|}{190} & \multicolumn{2}{|c|}{230} & \multicolumn{2}{|c|}{270} \\
\hline & & NT & PT & NT & PT & NT & PT & NT & PT & NT & PT & NT & PT \\
\hline \multirow{2}{*}{27} & $\mathrm{DF}$ & 28 & - & 29 & - & 30 & - & 29 & - & 30 & - & 30.5 & - \\
\hline & $\mathrm{CPO}$ & 25 & 26 & 26 & 27 & 27 & 28 & 28.5 & 29.5 & 29.5 & 30 & 30 & 30.5 \\
\hline \multirow{2}{*}{29} & DF & 28.5 & - & 29.5 & - & 30.2 & & 29.5 & - & 30.5 & - & 31 & - \\
\hline & $\mathrm{CPO}$ & 27 & 27.5 & 27.5 & 28 & 28.5 & 29 & 29.5 & 30 & 30 & 30.5 & 30.5 & 31 \\
\hline \multirow{2}{*}{30} & $\mathrm{DF}$ & 29 & - & 30 & - & 30.5 & - & 29 & - & 30 & - & 30.5 & - \\
\hline & $\mathrm{CPO}$ & 26.5 & 27 & 28.5 & 29 & 28.5 & 29 & 29 & 29.5 & 29.5 & 30 & 30 & 30.5 \\
\hline \multirow{2}{*}{31} & $\mathrm{DF}$ & 29.5 & - & 30 & - & 31 & - & - & - & - & - & - & - \\
\hline & $\mathrm{CPO}$ & 28.5 & 29 & 28 & 28.5 & 27.5 & 28 & - & - & - & - & - & - \\
\hline \multirow{2}{*}{32} & DF & 30 & & 30.5 & & 30.5 & & & & & & & \\
\hline & $\mathrm{CPO}$ & 27 & 28 & 27.5 & 28 & 28 & 28.5 & - & - & - & - & - & - \\
\hline 33 & DF & 31 & & 31 & & 30 & - & - & - & - & - & - & - \\
\hline
\end{tabular}

DF: diesel fuel, CPO: crude pongamia oil, NT: normal or room temperature, PT: preheat temperature.

TABle 3: The Variation of EGT at The Peak Load With Injection Timing and Injection Pressure in The Conventional and LHR Engines at Different Operating Conditions of The Vegetable Oil.

\begin{tabular}{|c|c|c|c|c|c|c|c|c|c|c|c|c|c|}
\hline \multirow{5}{*}{ Injection timing $\left({ }^{\circ} \mathrm{b}\right.$ TDC $)$} & \multirow{5}{*}{ Test fuel } & \multicolumn{12}{|c|}{ EGT at the peak load $\left({ }^{\circ} \mathrm{C}\right)$} \\
\hline & & \multirow{2}{*}{\multicolumn{6}{|c|}{$\begin{array}{c}\text { Conventional engine } \\
\text { Injection pressure (bars) }\end{array}$}} & \multirow{2}{*}{\multicolumn{6}{|c|}{$\begin{array}{l}\text { LHR engine } \\
\text { Injection pressure (bars) }\end{array}$}} \\
\hline & & & & & & & & & & & & & \\
\hline & & \multicolumn{2}{|c|}{190} & \multicolumn{2}{|c|}{230} & \multicolumn{2}{|c|}{270} & \multicolumn{2}{|c|}{190} & \multicolumn{2}{|c|}{230} & \multicolumn{2}{|c|}{270} \\
\hline & & NT & PT & NT & PT & NT & PT & NT & PT & NT & $\mathrm{PT}$ & NT & PT \\
\hline \multirow{2}{*}{27} & $\mathrm{DF}$ & 425 & - & 410 & - & 395 & - & 460 & - & 450 & - & 440 & - \\
\hline & $\mathrm{CPO}$ & 525 & 500 & 500 & 490 & 490 & 465 & 470 & 450 & 450 & 430 & 430 & 410 \\
\hline \multirow{2}{*}{29} & $\mathrm{DF}$ & & & & & & & 440 & & 430 & & 420 & \\
\hline & $\mathrm{CPO}$ & & & & & & & 430 & 410 & 410 & 390 & 390 & 370 \\
\hline \multirow{2}{*}{30} & DF & 410 & - & 400 & - & 385 & - & 460 & - & 450 & - & 440 & - \\
\hline & $\mathrm{CPO}$ & 500 & 490 & 490 & 480 & 425 & 415 & 470 & 450 & 450 & 430 & 430 & 410 \\
\hline \multirow{2}{*}{31} & DF & 400 & - & 390 & - & 375 & - & 450 & - & 445 & - & 440 & - \\
\hline & $\mathrm{CPO}$ & 450 & 415 & 435 & 425 & 445 & 435 & & & & & & \\
\hline \multirow{2}{*}{32} & $\mathrm{DF}$ & 390 & & 380 & & 380 & & 29 & - & 30 & - & 30.5 & - \\
\hline & $\mathrm{CPO}$ & 465 & 460 & 425 & 415 & 435 & 425 & - & - & - & - & - & - \\
\hline \multirow{2}{*}{33} & $\mathrm{DF}$ & 375 & - & 375 & - & 400 & - & - & - & - & - & - & - \\
\hline & EPO & 400 & 390 & 410 & 400 & 420 & 410 & - & - & - & - & - & - \\
\hline
\end{tabular}

DF: diesel fuel, CPO: crude pongamia oil, NT: normal or room temperature, PT: preheat temperature.

Figure 5 shows the variation of the volumetric efficiency (VE) with BMEP in CE and LHR engine with CPO at the recommended and optimized injection timings at an injection pressure of 190 bar. VE decreased with an increase of BMEP in both versions of the engine. This is due to increase of gas temperature with the load. At the recommended injection timing, VE in the both versions of the engine with CPO operation decreased at all loads when compared with $\mathrm{CE}$ with pure diesel operation. This is due increase of temperature of incoming charge in the hot environment created with the provision of insulation, causing reduction in the density and hence the quantity of air with LHR engine. VE increased marginally in CE and LHR engine at optimized injection timings when compared with recommended injection timings with CPO. This is due to decrease of unburnt fuel fraction in the cylinder leading to increase in VE in CE and reduction of gas temperatures with LHR engine. Table 4 shows the variation of VE with injection pressure and injection timing at different operating conditions of CPO with different configurations of the engine.

VE increased marginally with the advancing of the injection timing and with the increase of injection pressure in both versions of the engine. This is due to better fuel spray characteristics and evaporation at higher injection pressures 
Table 4: The Variation of Volumetric Efficiency (VE) at The Peak Load With The Injection Timing and Injection Pressure In The Conventional and LHR Engines, at Different Operating Conditions of The Vegetable Oil.

\begin{tabular}{|c|c|c|c|c|c|c|c|c|c|c|c|c|c|}
\hline \multirow{5}{*}{ Injection timing ( $\left.{ }^{\circ} \mathrm{bTDC}\right)$} & \multirow{5}{*}{ Test fuel } & \multicolumn{12}{|c|}{ Volumetric efficiency (\%) } \\
\hline & & \multirow{2}{*}{\multicolumn{6}{|c|}{$\begin{array}{l}\text { Conventional engine } \\
\text { Injection pressure (bars) }\end{array}$}} & \multirow{2}{*}{\multicolumn{6}{|c|}{$\begin{array}{c}\text { LHR engine } \\
\text { Injection pressure (bars) }\end{array}$}} \\
\hline & & & & & & & & & & & & & \\
\hline & & \multicolumn{2}{|c|}{190} & \multicolumn{2}{|c|}{230} & \multicolumn{2}{|c|}{270} & \multicolumn{2}{|c|}{190} & \multicolumn{2}{|c|}{230} & \multicolumn{2}{|c|}{270} \\
\hline & & NT & $\mathrm{PT}$ & NT & PT & NT & PT & NT & PT & NT & PT & NT & PT \\
\hline \multirow{2}{*}{27} & DF & 85 & - & 86 & - & 87 & - & 78 & - & 80 & - & 82 & - \\
\hline & $\mathrm{CPO}$ & 78.5 & 79.5 & 79.5 & 80.5 & 80.5 & 81.5 & 75.5 & 76.5 & 76.5 & 77.5 & 77.5 & 78.5 \\
\hline \multirow{2}{*}{29} & DF & & & & & & & 78.5 & & 80.5 & & 82.5 & \\
\hline & $\mathrm{CPO}$ & 80 & 81 & 81 & 82 & 82 & 83 & 77 & 77.5 & 78.5 & 79.5 & 79.5 & 80.5 \\
\hline \multirow{2}{*}{30} & DF & 86 & - & 87 & - & 88 & - & 76 & - & 77 & - & 78 & - \\
\hline & $\mathrm{CPO}$ & 79 & 80 & 80 & 81 & 81 & 82 & 75 & 75.5 & 76 & 76.5 & 77 & 77.5 \\
\hline \multirow{2}{*}{31} & $\mathrm{DF}$ & 87 & - & 87.5 & - & 89 & - & & & & & & \\
\hline & $\mathrm{CPO}$ & 79.5 & 80.5 & 80.5 & 81.5 & 81.5 & 82.5 & - & - & - & - & - & - \\
\hline \multirow{2}{*}{32} & $\mathrm{DF}$ & 87.5 & - & 88 & - & 87 & - & - & - & - & - & - & - \\
\hline & $\mathrm{CPO}$ & 79 & 80 & 80 & 81 & 81.5 & 82 & - & - & - & - & - & - \\
\hline 33 & DF & 89 & - & 89 & - & 86 & - & - & - & - & - & - & - \\
\hline
\end{tabular}

DF: diesel fuel, CPO: crude pongamia oil, NT: normal or room temperature, PT: preheat temperature.

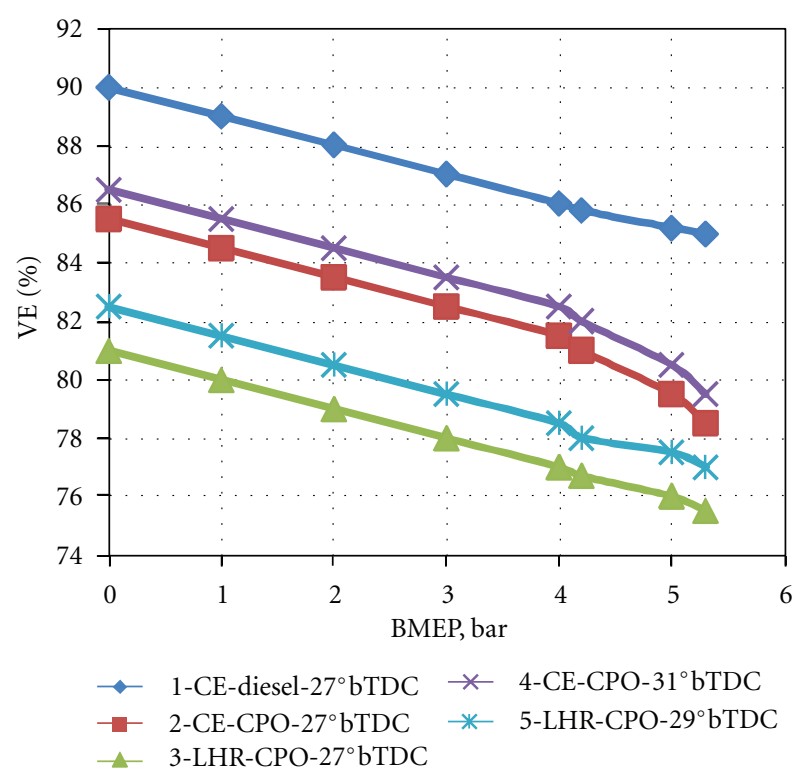

FIGURE 5: Variation of volumetric efficiency (VE) with brake mean effective pressure (BMEP) in conventional engine (CE) and lowheat-rejection (LHR) engine at recommend injection timing and optimized injection timings with crude pongamia oil (CPO) operation.

leading to marginal increase of VE. This is also due to the reduction of residual fraction of the fuel, with the increase of injection pressure. Preheating of the vegetable oil marginally improved VE in both versions of the engine, because of reduction of un-burnt fuel concentration with efficient combustion, when compared with the normal temperature of oil.

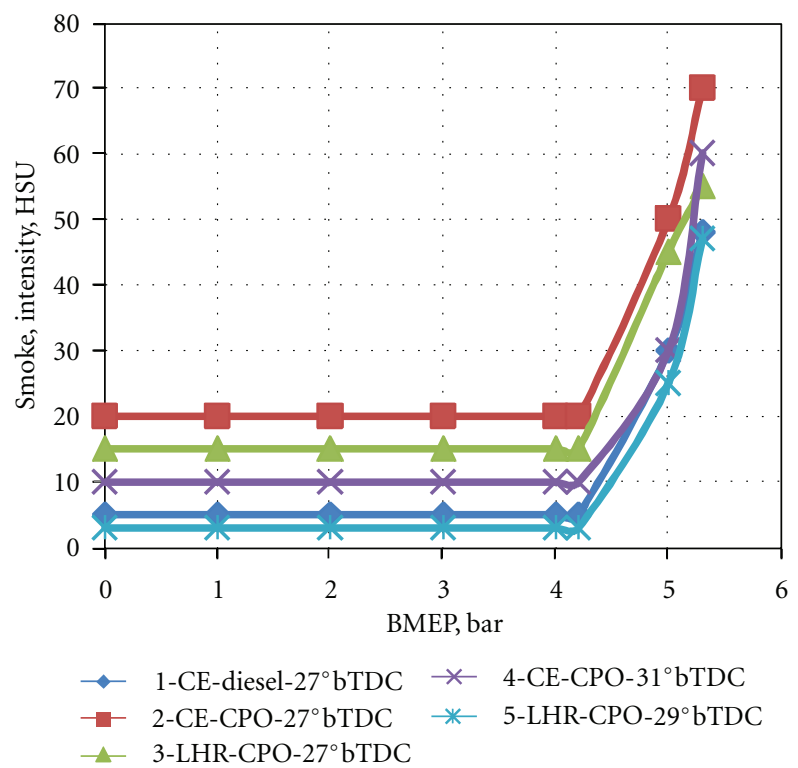

FIGURE 6: Variation of smoke intensity in Hartridge smoke unit (HSU) with brake mean effective pressure (BMEP) in conventional engine (CE) and low-heat-rejection (LHR) engine at recommend injection timing and optimized injection timings with crude pongamia oil (CPO) operation.

3.2. Pollution Levels. Figure 6 shows the variation of the smoke levels with BMEP in CE and LHR engine with vegetable oil operation at the recommended and optimized injection timings at an injection pressure of 190 bar. Drastic increase of smoke levels is observed at the peak load operation in CE at different operating conditions of the vegetable oil, compared with pure diesel operation on CE. This is due to the higher magnitude of the ratio of $\mathrm{C} / \mathrm{H}$ of $\mathrm{CPO}(1.13)$ 
Table 5: The Variation of Smoke Intensity at The Peak Load Operation Oils With The Injection Timing and Injection Pressure in The Conventional and LHR Engines, at different Operating Conditions of The Vegetable Oil.

\begin{tabular}{|c|c|c|c|c|c|c|c|c|c|c|c|c|c|}
\hline \multirow{5}{*}{ Injection timing ( $\left.{ }^{\circ} \mathrm{bTDC}\right)$} & \multirow{5}{*}{ Test fuel } & \multicolumn{12}{|c|}{ Smoke intensity (HSU) } \\
\hline & & \multirow{2}{*}{\multicolumn{6}{|c|}{$\begin{array}{l}\text { Conventional engine } \\
\text { Injection pressure (bars) }\end{array}$}} & \multirow{2}{*}{\multicolumn{6}{|c|}{$\begin{array}{c}\text { LHR engine } \\
\text { Injection pressure (bars) }\end{array}$}} \\
\hline & & & & & & & & & & & & & \\
\hline & & \multicolumn{2}{|c|}{190} & \multicolumn{2}{|c|}{230} & \multicolumn{2}{|c|}{270} & \multirow{2}{*}{$\begin{array}{l}190 \\
\text { NT }\end{array}$} & \multicolumn{3}{|c|}{230} & \multicolumn{2}{|c|}{270} \\
\hline & & NT & PT & NT & PT & NT & $\mathrm{PT}$ & & PT & NT & $\mathrm{PT}$ & NT & PT \\
\hline \multirow{2}{*}{27} & DF & 48 & - & 38 & - & 34 & - & 55 & - & 50 & - & 45 & - \\
\hline & $\mathrm{CPO}$ & 70 & 65 & 65 & 60 & 63 & 60 & 55 & 45 & 45 & 40 & 40 & 35 \\
\hline \multirow{2}{*}{29} & DF & 40 & - & 36 & - & 34 & & & & & & & \\
\hline & $\mathrm{CPO}$ & 68 & 64 & 63 & 59 & 60 & 57 & 47 & 40 & 40 & 35 & 35 & 30 \\
\hline \multirow{2}{*}{30} & DF & 36 & - & 34 & - & 32 & - & 45 & - & 42 & - & 41 & - \\
\hline & $\mathrm{CPO}$ & 67 & 64 & 60 & 57 & 61 & 58 & 57 & 50 & 50 & 45 & 45 & 40 \\
\hline \multirow{2}{*}{31} & DF & 33 & - & 32 & - & 30 & - & 43 & - & 41 & - & 40 & - \\
\hline & $\mathrm{CPO}$ & 60 & 57 & 57 & 54 & 54 & 60 & - & - & - & - & - & - \\
\hline \multirow{2}{*}{32} & DF & 32 & - & 31 & - & 32 & - & - & - & - & - & - & - \\
\hline & $\mathrm{CPO}$ & 72 & 69 & 69 & 66 & 64 & 62 & - & - & - & - & - & - \\
\hline 33 & DF & 30 & - & 30 & - & 35 & - & - & - & - & - & - & - \\
\hline
\end{tabular}

DF: diesel fuel, CPO: crude pongamia oil, NT: normal or room temperature, PT: preheat temperature.

when compared with pure diesel (0.45). The increase of smoke levels is also due to decrease of air-fuel ratios and VE with vegetable oil compared with pure diesel operation. Smoke levels are related to the density of the fuel. Since vegetable oil has higher density compared to diesel fuels, smoke levels are higher with vegetable oil. However, LHR engine marginally reduced smoke levels due to efficient combustion and less amount of fuel accumulation on the hot combustion chamber walls of the LHR engine at different operating conditions of the vegetable oil compared with the CE. Density influences the fuel injection system. Decreasing the fuel density tends to increase spray dispersion and spray penetration. Preheating of the vegetable oils reduced smoke levels in both versions of the engine, when compared with normal temperature of the vegetable oil. This is due to (i) the reduction of density of the vegetable oils, as density is directly proportional to smoke levels, (ii) the reduction of the diffusion combustion proportion in CE with the preheated vegetable oil, (iii) the reduction of the viscosity of the vegetable oil, with which the fuel spray does not impinge on the combustion chamber walls of lower temperatures rather than it directs into the combustion chamber.

Table 5 shows the variation of smoke levels with injection pressure and injection timing at different operating conditions of $\mathrm{CPO}$ with different configurations of the engine. Smoke levels decreased with increase of injection timings and with increase of injection pressure, in both versions of the engine, with different operating conditions of the vegetable oil. This is due to improvement in the fuel spray characteristics at higher injection pressures and increase of air entrainment, at the advanced injection timings, causing lower smoke levels.

Figure 7 shows the variation of the $\mathrm{NO}_{x}$ levels with BMEP in CE and LHR engine with vegetable oil at the recommended and optimized injection timings at an injection

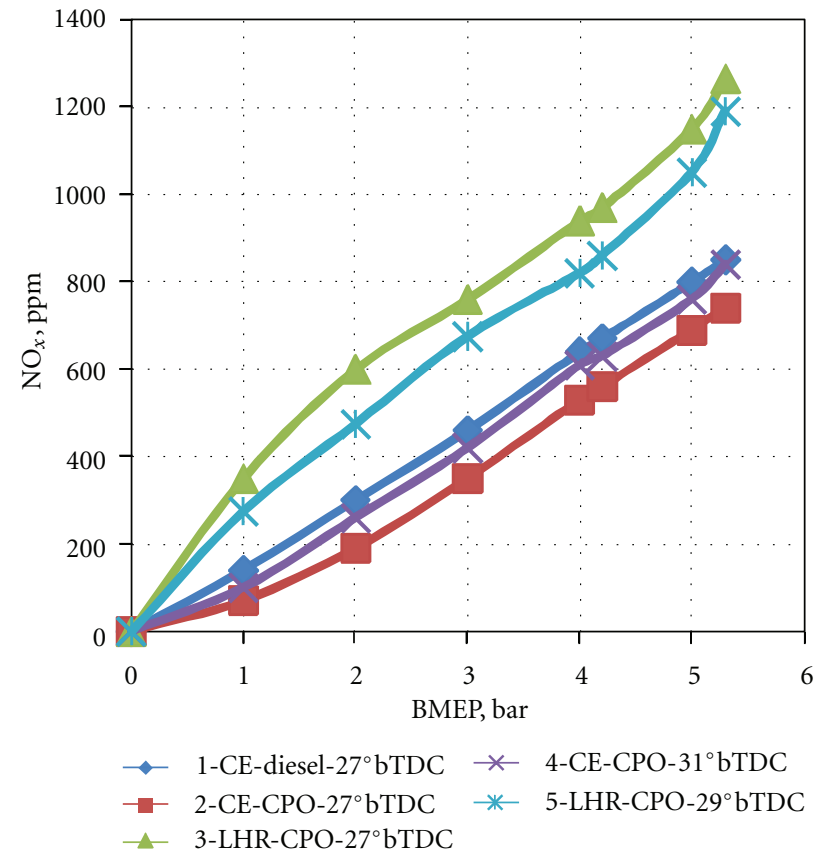

FIGURE 7: Variation of $\mathrm{NO}_{x}$ levels with brake mean effective pressure (BMEP) in conventional engine (CE) and low-heat-rejection (LHR) engine at recommend injection timing and optimized injection timings with crude pongamia oil (CPO) operation.

pressure of 190 bar. $\mathrm{NO}_{x}$ levels are lower in CE while they are higher in LHR engine at different operating conditions of the vegetable oil at the peak load when compared with diesel operation. This is due to lower heat release rate because of high duration of combustion causing lower gas temperatures with the vegetable oil operation on $\mathrm{CE}$, which reduced $\mathrm{NO}_{x}$ 
TABle 6: The Variation of $\mathrm{No}_{x}$ Levels at The Peak Load With The Injection Timing and Injection Pressure in The Conventional and LHR Engines at different Operating Conditions of The Vegetable Oil.

\begin{tabular}{|c|c|c|c|c|c|c|c|c|c|c|c|c|c|}
\hline \multirow{5}{*}{ Injection timing $\left({ }^{\circ} \mathrm{b}\right.$ TDC $)$} & \multirow{5}{*}{ Test fuel } & \multicolumn{12}{|c|}{$\mathrm{NO}_{x}$ levels (ppm) } \\
\hline & & \multirow{2}{*}{\multicolumn{6}{|c|}{$\begin{array}{l}\text { Conventional engine } \\
\text { Injection pressure (bars) }\end{array}$}} & \multirow{2}{*}{\multicolumn{6}{|c|}{$\begin{array}{c}\text { LHR engine } \\
\text { Injection pressure (bars) }\end{array}$}} \\
\hline & & & & & & & & & & & & & \\
\hline & & \multicolumn{2}{|c|}{190} & \multicolumn{2}{|c|}{230} & \multicolumn{2}{|c|}{270} & \multicolumn{2}{|c|}{190} & \multicolumn{2}{|c|}{230} & \multicolumn{2}{|c|}{270} \\
\hline & & NT & PT & NT & PT & NT & PT & NT & PT & NT & $\mathrm{PT}$ & NT & PT \\
\hline \multirow{2}{*}{27} & DF & 850 & - & 810 & - & 770 & - & 1300 & - & 1280 & - & 1260 & - \\
\hline & $\mathrm{CPO}$ & 740 & 700 & 700 & 660 & 660 & 620 & 1265 & 1250 & 1235 & 1220 & 1200 & 1185 \\
\hline \multirow{2}{*}{29} & DF & 900 & - & 860 & - & 820 & - & & & & & & \\
\hline & $\mathrm{CPO}$ & 760 & 720 & 725 & 680 & 680 & 640 & 1190 & 1170 & 1170 & 1140 & 1140 & 1120 \\
\hline \multirow{2}{*}{30} & DF & 935 & - & 900 & - & 860 & - & 1225 & - & 1205 & - & 1185 & - \\
\hline & $\mathrm{CPO}$ & 790 & 750 & 750 & 710 & 710 & 670 & 1240 & 1210 & 1210 & 1190 & 1190 & 1160 \\
\hline \multirow{2}{*}{31} & DF & 1020 & - & 980 & - & 940 & - & 1150 & - & 1130 & - & 1110 & - \\
\hline & $\mathrm{CPO}$ & 840 & 810 & 810 & 770 & 770 & 730 & - & - & - & - & - & - \\
\hline \multirow{2}{*}{32} & DF & 1105 & - & 1060 & - & 1020 & - & - & - & - & - & - & - \\
\hline & $\mathrm{CPO}$ & 1000 & 980 & 960 & 920 & 920 & 880 & - & - & - & - & - & - \\
\hline 33 & DF & 1190 & - & 1150 & - & 1110 & - & - & - & - & - & - & - \\
\hline
\end{tabular}

DF: diesel fuel, CPO: crude pongamia oil, NT: normal or room temperature, PT: preheat temperature.

TABle 7: Variation of PP, MRPR, TOPP, and TOMRPR with Injection Timing and Injection Pressure at the Peak Load Operation of CE and LHR Engine with Vegetable Oil Operation.

\begin{tabular}{|c|c|c|c|c|c|c|c|c|c|c|c|c|c|c|c|c|c|}
\hline \multirow{4}{*}{$\begin{array}{l}\text { Injection } \\
\text { timing } \\
\left({ }^{\circ} \text { bTDC)/test }\right. \\
\text { fuel }\end{array}$} & \multirow{4}{*}{$\begin{array}{l}\text { Engine } \\
\text { version }\end{array}$} & \multicolumn{4}{|c|}{ PP (bar) } & \multicolumn{4}{|c|}{ MRPR (bar/deg) } & \multicolumn{4}{|c|}{ TOPP (deg) } & \multicolumn{4}{|c|}{ TOMRPR (deg) } \\
\hline & & \multicolumn{4}{|c|}{ Injection pressure (bar) } & \multicolumn{4}{|c|}{ Injection pressure (bar) } & \multicolumn{4}{|c|}{ Injection pressure (bar) } & \multicolumn{4}{|c|}{ Injection pressure (bar) } \\
\hline & & \multicolumn{2}{|c|}{190} & \multicolumn{2}{|c|}{270} & \multicolumn{2}{|c|}{190} & \multicolumn{2}{|c|}{270} & \multicolumn{2}{|c|}{190} & \multicolumn{2}{|c|}{270} & \multicolumn{2}{|c|}{190} & \multicolumn{2}{|c|}{270} \\
\hline & & NT & PT & NT & PT & NT & PT & NT & PT & NT & PT & NT & PT & NT & PT & NT & PT \\
\hline \multirow{2}{*}{ 27/diesel } & $\mathrm{CE}$ & 50.4 & - & 53.5 & - & 3.1 & - & 3.4 & - & 9 & - & 8 & - & 0 & 0 & 0 & 0 \\
\hline & LHR & 48.1 & - & 53.0 & - & 2.9 & - & 3.1 & - & 10 & - & 9 & - & 0 & 0 & 0 & 0 \\
\hline \multirow{2}{*}{$27 / \mathrm{CPO}$} & $\mathrm{CE}$ & 45.9 & 47.9 & 48.1 & 49.4 & 2.1 & 2.2 & 2.8 & 2.9 & 12 & 11 & 12 & 10 & 1 & 1 & 1 & 1 \\
\hline & LHR & 58.8 & 59.7 & 62.1 & 63.8 & 3.2 & 3.3 & 3.4 & 3.5 & 11 & 10 & 10 & 9 & 1 & 1 & 1 & 1 \\
\hline $30 / \mathrm{CPO}$ & LHR & 60.5 & 61.8 & 64.1 & 64.8 & 3.3 & 3.4 & 3.5 & 3.6 & 10 & 9 & 9 & 9 & 0 & 0 & 0 & 0 \\
\hline $32 / \mathrm{CPO}$ & $\mathrm{CE}$ & 50.4 & 51.7 & & & 3.0 & 3.1 & & & 11 & 10 & & & 0 & 0 & & \\
\hline
\end{tabular}

CPO: crude pongmia oil, CE: conventional engine, LHR: low heat rejection, NT: normal temperature, PT: preheated temperature.

levels. Increase of combustion temperatures with the faster combustion and improved heat release rates in LHR engine cause higher $\mathrm{NO}_{x}$ levels. As expected, preheating of the vegetable oil decreased $\mathrm{NO}_{x}$ levels in $\mathrm{CE}$ and reduced the same in LHR engine when compared with the normal vegetable oil. This is due to improved air fuel ratios and decrease of combustion temperatures leading to decrease $\mathrm{NO}_{x}$ emissions in the CE and decrease of combustion temperatures in the LHR engine with the improvement in air-fuel ratios leading to decrease $\mathrm{NO}_{x}$ levels in LHR engine.

Table 6 shows the variation of $\mathrm{NO}_{x}$ levels with injection pressure and injection timing at different operating conditions of CPO with different configurations of the engine. $\mathrm{NO}_{x}$ levels increased with the advancing of the injection timing and with increase of injection pressure in CE with different operating conditions of vegetable oil. Residence time and availability of oxygen had increased, when the injection timing is advanced with the vegetable oil operation, which caused higher $\mathrm{NO}_{x}$ levels in CE. With the increase of injection pressure, fuel droplets penetrate and find oxygen counterpart easily. Turbulence of the fuel spray increased the spread of the droplets which causes the increase the gas temperatures marginally thus leading to increase in $\mathrm{NO}_{x}$ levels as the availability of oxygen and increase of gas temperatures are the two factors responsible for formation of $\mathrm{NO}_{x}$ levels. However, marginal decrease of $\mathrm{NO}_{x}$ levels is observed in LHR engine, due to decrease of combustion temperatures, which is evident from the fact that thermal efficiency is increased in LHR engine due to the reason sensible gas energy is converted into actual work in LHR engine, when the injection timing is advanced and with increase of injection pressure. 
3.3. Combustion Characteristics. Table 7 presents the comparison on the magnitudes of PP, MRPR, TOPP, and TOMRPR with the injection timing and injection pressure, at the peak load operation of CE and LHR engine with vegetable oil operation. Peak pressures are lower in $\mathrm{CE}$ while they were higher in LHR engine at the recommended injection timing and pressure, when compared with pure diesel operation on CE. This is due to increase of ignition delay, as vegetable oils require large duration of combustion. Meanwhile, the piston started making downward motion thus increasing volume when the combustion takes place in CE. LHR engine increased the mass burning rate of the fuel in the hot environment leading to production of higher peak pressures. The advantage of using LHR engine for vegetable oil is obvious as it could burn low cetane and high viscous fuels. Peak pressures increased with the increase of injection pressure and with the advancing of the injection timing in both versions of the engine, with the vegetable oil operation. Higher injection pressure produces smaller fuel particles with low surface-to-volume ratio, giving rise to higher PP. With the advancing of the injection timing to the optimum value with the $\mathrm{CE}$, more amount of the fuel accumulated in the combustion chamber due to increase of ignition delay as the fuel spray found the air at lower pressure and temperature in the combustion chamber. When the fuel-air mixture burns, it produces more combustion temperatures and pressures due to increase of the mass of the fuel. With LHR engine, peak pressures increase due to effective utilization of the charge with the advancing of the injection timing to the optimum value. The magnitude of TOPP decreased with the advancing of the injection timing and with increase of injection pressure in both versions of the engine, at different operating conditions of vegetable oils. TOPP is more with different operating conditions of vegetable oils in $\mathrm{CE}$, when compared with pure diesel operation on CE. This is due to higher ignition delay with the vegetable oil when compared with pure diesel fuel. This once again established the fact by observing lower peak pressures and higher TOPP that CE with vegetable oil operation showed the deterioration in the performance when compared with pure diesel operation on CE. Preheating of the vegetable oil showed lower TOPP, compared with vegetable oil at normal temperature. This once again confirmed by observing the lower TOPP and higher PP; the performance of the both versions of the engine is improved with the preheated vegetable oil compared with the normal vegetable oil. This trend of increase of MRPR and decrease of TOMRPR indicated better and faster energy substitution and utilization by vegetable oils, which could replace $100 \%$ diesel fuel. However, these combustion characters are within the limits; hence, the vegetable oils could be effectively substituted for diesel fuel.

\section{Conclusions}

Vegetable oil operation at $27^{\circ} \mathrm{bTDC}$ on $\mathrm{CE}$ showed the deterioration in the performance, while LHR engine showed improved performance, when compared with pure diesel operation on CE. Preheating of the vegetable oils improved performance when compared with normal vegetable oils in both versions of the engine. Improvement in the performance is observed with the advancing of the injection timing and with the increase of injection pressure with the vegetable oil operation on both versions of the engine. CE with crude vegetable oil operation showed the optimum injection timing at $31^{\circ} \mathrm{bTDC}$, while the LHR engine showed the optimum injection at $29^{\circ} \mathrm{bTDC}$ at an injection pressure of 190 bars. At the recommended injection timing and pressure, crude vegetable oil operation on $\mathrm{CE}$ increased smoke levels and decreased $\mathrm{NO}_{x}$ levels, while LHR engine decreased smoke levels and increased $\mathrm{NO}_{x}$ levels when compared with pure diesel operation on CE. Preheating of the crude vegetable oil decreased smoke levels and $\mathrm{NO}_{x}$ levels slightly in both versions of the engine. $\mathrm{CE}$ with vegetable oil operation decreased smoke levels and increased $\mathrm{NO}_{x}$ levels, while LHR engine decreased smoke and $\mathrm{NO}_{x}$ levels with the advancing of the injection timing. With increase in injection pressure, smoke and $\mathrm{NO}_{x}$ levels decreased in both versions of the engine. Lower peak pressures and more TOPP are observed with normal crude vegetable oil in CE. LHR engine with vegetable oil operation increased PP and decreased TOPP when compared with CE. Preheating increased PP and decreased TOPP when compared with normal vegetable oil operation on both versions of the engine. Lower peak pressures and lower peak gas temperatures are predicted in CE, while higher peak pressures and higher gas temperatures are in the LHR engine with crude vegetable oil operation at the recommended injection timing and pressure.

\section{Acknowledgments}

The authors thank authorities of the Chaitanya Bharathi Institute of Technology, Hyderabad, for providing facilities for carrying out research work. Financial assistance provided by All India Council for Technical Education (AICTE), New Delhi, is greatly acknowledged.

\section{References}

[1] K. Pramanik, "Properties and use of jatropha curcas oil and diesel fuel blends in compression ignition engine," Renewable Energy, vol. 28, no. 2, pp. 239-248, 2003.

[2] S. Sinha and A. K. Agarawal, "Performance evaluation of a biodiesel (rice bran oil methyl ester) fuelled transportation diesel engine," Tech. Rep. 2005- 01-1730, SAE, New York, NY, USA, 2005.

[3] M. Pugazhvadivu and K. Jeyachandran, "Investigations on the performance and exhaust emissions of a diesel engine using preheated waste frying oil as fuel," Renewable Energy, vol. 30, no. 14, pp. 2189-2202, 2005.

[4] A. K. Agarwal, "Biofuels (alcohols and biodiesel) applications as fuels for internal combustion engines," Progress in Energy and Combustion Science, vol. 33, no. 3, pp. 233-271, 2007.

[5] M. K. Gajendra Babu and C. Kumar, "Experimental investigations on a karanja oil methyl ester fuelled DI diesel engine," Tech. Rep. 2006-01-0238, SAE, New York, NY, USA, 2006.

[6] J. Suryawanshi, "Performance and emission characteristics of CI engine fueled by coconut oil methyl ester," Tech. Rep. 200632-0077, SAE, New York, NY, USA, 2006. 
[7] D. Agarwal and A. K. Agarwal, "Performance and emissions characteristics of Jatropha oil (preheated and blends) in a direct injection compression ignition engine," Applied Thermal Engineering, vol. 27, no. 13, pp. 2314-2323, 2007.

[8] R. D. Misra and M. S. Murthy, "Straight vegetable oils usage in a compression ignition engine-a review," Renewable and Sustainable Energy Reviews, vol. 14, no. 9, pp. X3005-X3013, 2010.

[9] R. Kamo et al., "Injection characteristics that improve performance of ceramic-coated diesel engine," Tech. Rep. 1999-010972, SAE, New York, NY, USA, 1999.

[10] S. Jaichandar and P. Tamilporai, "Low heat rejection enginesan overview," Tech. Rep. 2003-01-0405, SAE, New York, NY, USA, 2003.

[11] S. Ahmaniemi, J. Tuominen, M. Vippola et al., "Characterization of modified thick thermal barrier coatings," Journal of Thermal Spray Technology, vol. 13, no. 3, pp. 361-369, 2004.

[12] E. Büyükkaya, T. Engin, and M. Cerit, "Effects of thermal barrier coating on gas emissions and performance of a LHR engine with different injection timings and valve adjustments," Energy Conversion and Management, vol. 47, no. 9-10, pp. 1298-1310, 2006.

[13] J. Dhinagar, B. Nagalingam, and K. V. Gopala Krishnan, "A comparative study of the performance of a low heat rejection engine with four different levels of insulation," in Proceedings of the 4th International Conference on Small Engines and Fuels, pp. 121-126, Chang Mai, Thailand, 1993.

[14] T. Bhaskar, B. Nagalingam, and K. V. Gopala Krishan, "The effect of two ignition improving additives on the performance of jatropha oil in low heat rejection diesel engine," in Proceedings of 4th International Conference on Small Engines and their Fuels, pp. 14-19, Chang Mai, Thailand, 1993.

[15] S. Jabez Dhinagar, B. N. Nagalingam, and K. V. Gopalakrishna, "Experimental investigation of non-edible vegetable oil operation in a lhr diesel engine for improved performance," Tech. Rep. 932846, SAE, New York, NY, USA, 1993.

[16] H. Hazar, "Effects of biodiesel on a low heat loss diesel engine," Renewable Energy, vol. 34, no. 6, pp. 1533-1537, 2009.

[17] B. Rajendra Prasath, P. Tamilporai, and M. F. Shabir, "Analysis of combustion, performance and emission characteristics of low heat rejection engine using biodiesel," International Journal of Thermal Sciences, vol. 49, no. 12, pp. 2483-2490, 2010. 

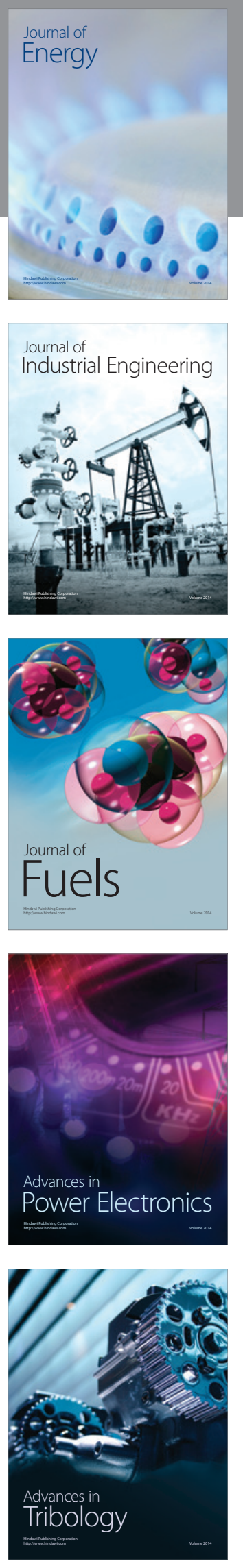
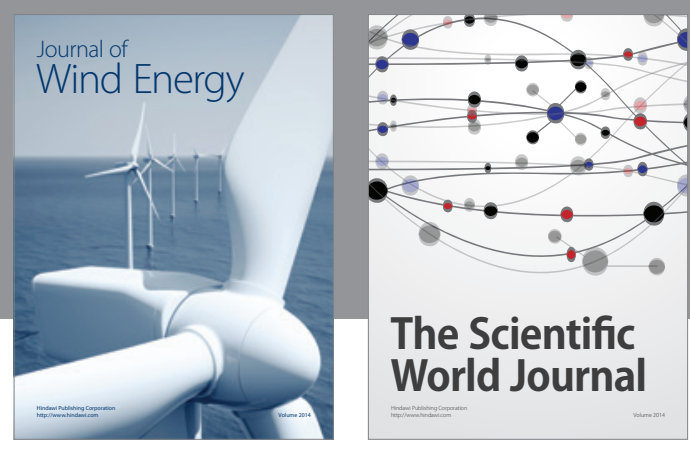

The Scientific World Journal

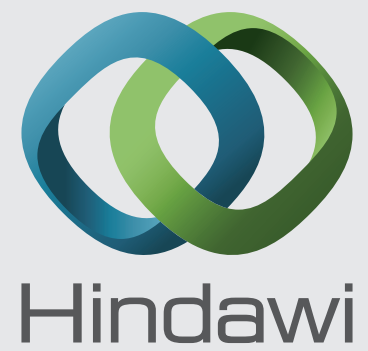

Submit your manuscripts at http://www.hindawi.com
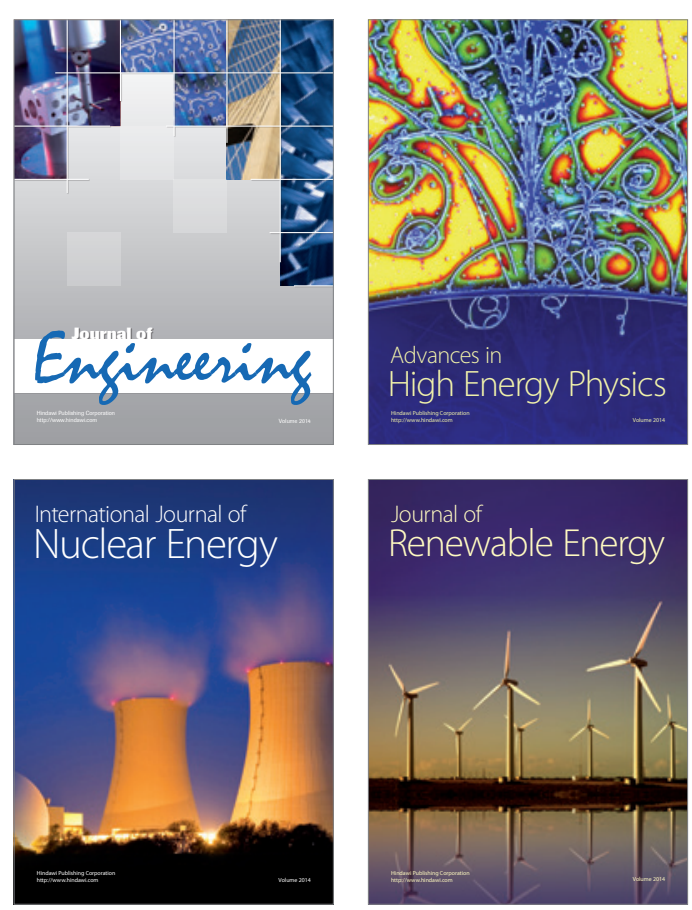

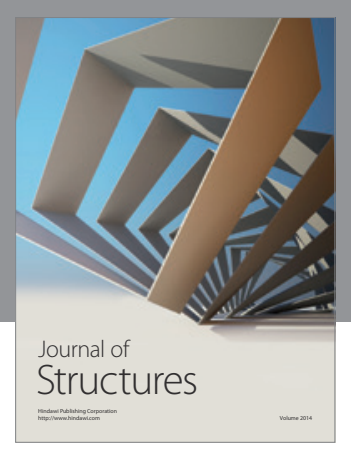

Rotating
Mechinery
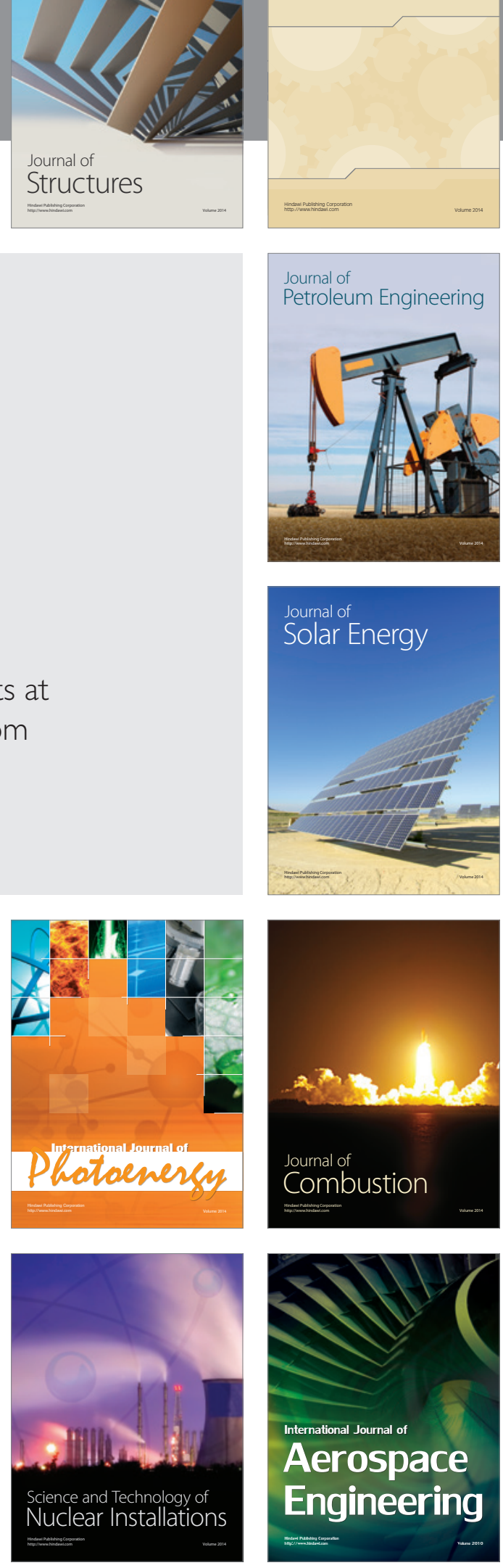